Simakov, E. A. (1983): About post-irradiation reparation of cytogenetic damages in plantlets of different potatos' forms. Radiobiology 23 (5): 703-706. (in Russian)

StePANOva, E. I. and E. A. VANYURIKHINA (1993): Clinical and cytogenetic characterization of children whose fathers suffered from acute radiation sickness of the $1^{\text {st }}$ and $2^{\text {nd }}$ stages due the accident at the Chernobyl
Nuclear power plant. Cytology and Genetics 27 (4): 10-13.

Trott K. R. and A. TeIBe (1998): Lack of specificity of chromosome breaks resulting from radiation-induced genomic instability in Chinese hamster cells. Radiat. Environ Biophys. 37: 171-176.

\title{
Identification of Atractylodes japonica and A. macrocephala by RAPD analysis and SCAR Markers
}

\author{
By M. K. $\mathrm{HUH}^{1), *)}$ and K. H. BANG ${ }^{2)}$
}

(Received 24 ${ }^{\text {th }}$ April 2005)

\begin{abstract}
The Chinese plant, "Packchul", (Atractylodes japonica or A. macrocephala), is a very important Chinese medicinal herb plant and is called Sabju in Korea. The levels of the active components are different between these two species, but these medicines are sold in Korean herbal markets without discrimination. This study was carried out to develop a method that could be used to discriminate between $A$. japonica and A. macrocephala based on molecular markers. To discriminate between A. japonica and A. macrocephala, RAPD analyses were used to develop SCAR markers. Eighteen species-specific RAPD bands were obtained from 52 OPERON and URP primer sets. Two SCAR markers were developed from these RAPD clones. Both SCAR markers were cloned into pGEM-T-Easy vectors and then subjected to nucleotide sequence analysis and designated $A j R 1$ $(1,117 \mathrm{bp})$ and $A m R 1$ (1,325 bp). These two markers were sufficient to discriminate between samples of A. japonica and A. macrocephala.
\end{abstract}

Key words: Atractylodes japonica, A. macrocephala, RAPD, SCAR.

\section{Introduction}

"Packchul", which is commonly called atractylodis rhizoma, white atractylodes rhizome, or simply atractylodes, is used as a Chinese herbal medicine. Packchul consists of two species with the botanical names of Atractylodes japonica Koidz and A. macrocephala Koidz. It has been reported that Packchul has various health benefits, such as regulating the function of the stomach, replenishing vigor, strengthening the spleen, stopping sweating, and preventing miscarriage (SАKАмото et al., 1996).

1) Department of Molecular Biology, Dongeui University, Busan 614-714, Korea.

$\left.{ }^{2}\right)$ Division of Ginseng \& Medical Crops, National Institute of Crop Science, RDA, Suwon 441-857, Korea.

*) Corresponding author: MAN KYU HuH, Fax: +82-51-890-1521, Tel: +82-51-890-1529, E-mail: mkhuh@deu.ac.kr
The Korean botanical name "Sabju" represents the genus Atractylodes of the family Compositae and is divided into two types, "Packchul" and "Changchul". In Korean pharmacopoeia. Packchul is defined as the rhizome and peeled rhizome of $A$. japonica and Changchul is defined as those of A. lancea (Thunb.) DC. or A. chinensis Kitamura. In the Chinese pharmacopoeia, however, Packchul includes not only A. macrocephala, but also includes $A$. ovata DC. and Changchuls, which includes A. japonica, A. lancea, and A. chinensis (KIM et al., 1998). This discrepancy has caused a confusion and difficulty in the use of these herbal medicines.

During the last decade several novel DNA markers have been developed for genome analysis. Among the types of molecular markers, "random amplified polymorphic DNA" (RAPD) techniques have greatly improved detection methods since their first reported use in 1990 (Williams et al., 1990; NiCESE et al., 1998).

The RAPD technique is sensitive to reaction conditions, which results in poor reproducibility. To overcome the problems associated with RAPD and to improve their utility in marker-assisted selection, longer primers have been developed from RAPD fragments (PARAN and MiCHELMORE, 1993). These longer primers generate a "sequence-characterized amplified region" (SCAR), which can be particularly useful to follow the inheritance of the marked region of the genome. SCAR markers are preferred over RAPD because they detect only a single locus, their amplification is less sensitive to reaction conditions, and they can potentially be converted into allele-specific markers. SCAR markers have been developed for crops (DENG et al., 1997; HERNANDEZ et al., 1999; ARDIEL, 2002). The conversion of a linked marker to SCAR has been applied successfully in a number of cases involving RAPD (NAQVI and CHATTOO, 1996; BARRET et al., 1998; LAHOGUE et al., 1998).

In Atractylodes species, several studies using RAPD and RFLP analyses have been reported but the use of RAPD analysis and SCAR markers to discriminate between the species has not been reported. 
The rapid expansion of industries producing foods for health improvement and materials for oriental medicine has resulted in a decrease in the use of Packchul as a herbal medicine. On the other hand its industrial use is increasing. As a result of this change, Chinese Packchul (A. macrocephala) was ranked second in herbal medicine imports following licorice. It has been reported that imported Chinese Packchul was less valuable than Korean A. japonica with respect to their components and effects. Korean Packchul is currently trading at a price 10 times higher than the Chinese source. These two species can be identified by leaf morphology, flower color and size, and rhizome shape (BANG et al., 2003). However, it is impossible to distinguish between the two species when the rhizomes are sliced. Therefore, in herbal markets the Chinese Packchul is illegally sold either without the correct label or by mixing it with Korean Packchul. The aim of this study is to develop methods to distinguish the differences between the two species, A. japonica and A. macrocephala, at the molecular level.

\section{Materials and Methods}

\section{Materials and DNA extraction}

A. japonica and A. macrocephala were used for RAPD analyses. Plants of $A$. japonica were collected from eight regions in Korea and imported plants of A. macrocephala were obtained from China. The plants of $A$. japonica and $A$. macrocephala were cultivated according to the standard cultural practices of National Crop Experiment Station, Suwon, Kyonggi Province, Korea from 2001 to 2002 (Table 1).

The 30 young plants per source were used for RAPD analyses. Samples were frozen in liquid nitrogen and ground in a mortar to a fine powder. DNA was extracted using QIAGEN DNeasy Plant Kit (Doyle and Doyle, 1987).

\section{RAPD analysis}

The RAPD analysis was carried out using the following mixture: $50 \mathrm{ng}$ genomic DNA, $0.5 \mu \mathrm{M}$ primer $250 \mu \mathrm{M}$ dNTPs, 5 U Taq-polymerase, 10x buffer, and distilled water.

Forty random primers supplied by OPERON Technologies Inc. (Alameda, CA) and 12 primers (Seolin Technologies Inc., Korea) were used for RAPD the analysis. The amplification reaction was carried out using a DNA Thermal Cycler (Applied Biosystematics). Amplification products were analyzed by electrophoresis on $1.5 \%$ agarose gel in TBE buffer and detected by ethidium bromide staining under UV lights.

All the reactions were repeated twice and only reproducible bands were scored for analyses. Only clear and distinct bands were scored both in agarose gels, attributing ' 1 ' to the presence and ' 0 ' to the absence of a band. The following genetic parameters were calculated using a POPGENE computer program (ver. 1.31) developed by YEH et al. (1999): the percentage of polymorphic loci $(P \mathrm{p})$, mean numbers of alleles per locus $(A)$, and gene diversity $(H)(\mathrm{NEI}, 1973)$. The NTSYs-pc software was used for statistical analysis of data. The unweighted pair-group method with arithmetic means (UPGMA) was used to construct dendrograms.

\section{$S C A R$ analysis}

To convert a selected RAPD band to a SCAR marker, each RAPD band was isolated from agarose gel using a Geneclean II kit, and the isolated DNA was separated by electrophoresis in $1.0 \%$ agarose gel to confirm DNA

Table 1. - Samples used for RAPD analyses. The percentage of polymorphism $(P \mathrm{p})$, mean number of alleles per locus $(A)$, and gene diversity $(H)$.

\begin{tabular}{|c|c|c|c|c|}
\hline Codes & Collection sites & $P p$ & $\bar{A}$ & $H$ \\
\hline \multicolumn{5}{|c|}{ Atractylodes japonica } \\
\hline AJ-1 & Kumsan, Chungnam Province & 26.6 & 1.28 & 0.12 \\
\hline $\mathrm{AJ}-2$ & Uiseong, Kyongsang Province & 25.4 & 1.41 & 0.14 \\
\hline AJ-3 & Inje, Gangwon Province & 23.5 & 1.27 & 0.12 \\
\hline AJ-4 & Hwaseong, Kyonggi Province & 27.3 & 1.20 & 0.14 \\
\hline AJ-5 & Suwon, Kyonggi Province & 28.1 & 1.36 & 0.12 \\
\hline AJ-6 & Gapyong, Kyonggi Province & 30.3 & 1.28 & 0.11 \\
\hline AJ-7 & Pochon, Kyonggi Province & 22.7 & 1.15 & 0.10 \\
\hline AJ-8 & Pyongchang, Gangwon Province & 31.1 & 1.61 & 0.13 \\
\hline Mean & & 26.9 & 1.32 & 0.12 \\
\hline \multicolumn{5}{|c|}{ A. macrocephala } \\
\hline Am-1 & China & 25.5 & 1.27 & 0.11 \\
\hline
\end{tabular}


Table 2. - RAPD analysis and SCAR markers used for discrimination of A. japonica and A. macrocephala.

\begin{tabular}{ccc}
\hline \multirow{2}{*}{ RAPD } & Sequences of SCAR marker primer & Size of RAPD \\
& & markers (bp) \\
\hline \multirow{2}{*}{ AjR1 } & Forward primer: 5' GGAAGGAATCGAGAAGGCTAACGC 3' & \multirow{2}{*}{1117} \\
& Reverse primer: 5' AATGGCCGCCATGGTTGAAG 3' & \\
\hline \multirow{2}{*}{$A m R 1$} & Forward primer: 5' CCGTCAATAAACCAAACATCACTG 3' & \multirow{2}{*}{1325} \\
& Reverse primer: 5' TCCTTGATGCCTACCTCCTGTTAG 3' & \\
\hline
\end{tabular}

AjR1 stands for Atractylodes japonica.

AmR1 stands for A. macrocephala.

size. The DNA were then ligated into the pGEM-T-Easy vector (Promega) and transformed into E. coli DH5 $\alpha$. Nucleotide sequences were determined using the automatic DNA sequencer (ABI377). The similarities of DNA sequence data were analyzed using BLAST (ALTSCHUL et al., 1997).

The SCAR marker sequences were designed by identifying the original $10 \mathrm{bp}$ sequences of the RAPD primer and adding the next approximately $10 \mathrm{bp}$ in the DNA sequence. These species-specific SCAR primer were then synthesized by Seolin Technologies Inc. Each of the designed SCAR primer pairs (one forward and one reverse SCAR primer) was tested by means of sub samples of both species. To establish the optimum annealing temperature, five annealing temperatures from 35 to $39^{\circ} \mathrm{C}$, with one degree increase were tested with the PCR condition of $5 \mathrm{ng}$ template DNA, $4 \mu \mathrm{M}$ primer, 0.5 unit Taq DNA Polymerase in a $20 \mu$ l total reaction volume. The optimum PCR condition was found to be an initial denaturation for two minutes at $94^{\circ} \mathrm{C}$, followed by 35 cycles of 30 seconds at $94^{\circ} \mathrm{C}, 30$ seconds $39^{\circ} \mathrm{C}$, and 60 seconds $72^{\circ} \mathrm{C}$; and a final five minutes of extension at $72{ }^{\circ} \mathrm{C}$.

\section{Results}

\section{$R A P D$ analysis}

To identify the variation of the RAPD patterns between two Atracylodes species, 52 different random primers were applied to the genomic DNAs of $A$. japonica and A. macrocephala.

Ten primers out of the 52 primers could be used to discriminate between the subspecies. Eighteen polymorphic bands out of 67 scored DNA fragments were generated using these primers. The number of polymorphic bands ranged from one to three per primer and the amplified products varied between 0.6 and $2.4 \mathrm{kbp}$. Five fragments are specific for $A$. japonica and do not show at A. macrocephala. On the other hand, three fragments are specific for A. macrocephala. These species-specific DNA fragments seemed to be useful to discriminate between A. japonica and A. macrocephala and were used to develop the SCAR markers.
Although the typical populations of $A$. japonica were small, isolated, and patchily distributed for accessions, they maintained a high level of genetic diversity $(H)$ (Table 1). In a simple measure of intraspecies variability by the percentage of polymorphic bands, the AJ-7 exhibited the lowest variation $(22.7 \%)$. The AJ-8 showed the highest $(31.1 \%)$. The phenotypic frequency of each band was calculated and used in estimating genetic diversity $(H)$ within populations. The mean $H$ of $A$. japonica (1.606) was higher than that of $A$. macrocephala.

\section{$S C A R$ analysis}

Eighteen species-specific RAPD bands were obtained from 52 OPERON and URP primer sets. Five bands were found specific to $A$. japonica, whereas three bands were specific to $A$. macrocephala. The distinct two primer pairs, $A j R 1$ and $A m R 1$, were designed from the sequences of RAPD fragments. The primer pairs, $A j R 1$ and $A m R 1$, were the amplified genomic DNAs of A. japonica and A. macrocephala.

The DNA sequence AjR1 consists of $1,117 \mathrm{bp}$ nucleotides and was specific to $A$. japonica. The fragment amplified the expected 1,200 bp DNA bands in individuals from $A$. macrocephala, whereas no products were detected in individuals from $A$. japonica. The DNA sequences of $A m R 1$ consist of $1,325 \mathrm{bp}$ nucleotides and were specific in A. macrocephala (Fig. 2).

Searching (in) GenBank revealed that the 1,117 bp (868-1,010 bp) DNA fragment from marker AjR1 share $78 \%$ nucleotides in the complete sequence of the Medicago truncatula clone mth1-808. However, the

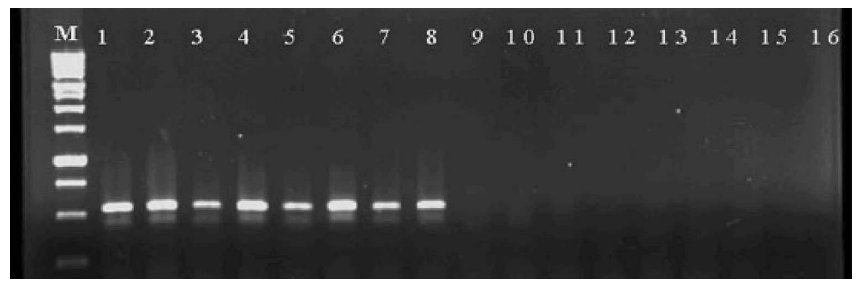

Figure 1. - Ideogram of species-specific DNA fragments obtained by RAPD analysis and RAPD AjR1 sequences. M, molecular weight of polymorphic DNA; Lane 1-8, 8 different accessions of A. japonica; Lane 9-16, A. macrocephala. 


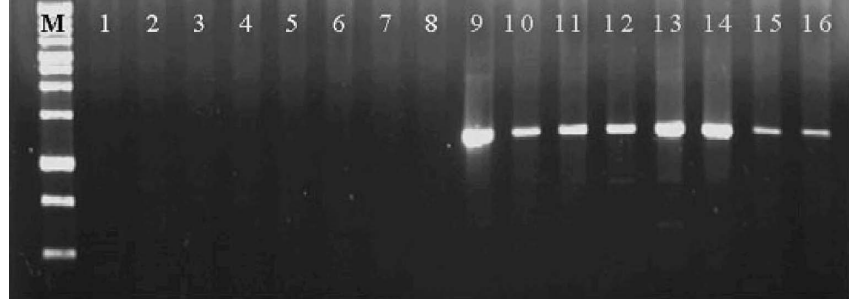

Figure 2. - Ideogram of species-specific DNA fragments obtained by RAPD analysis and RAPD AmR1 sequences. M, molecular weight of polymorphic DNA; Lane 1-8, A. japonica; Lane 9-16, A. macrocephala.

sequences of $A m R 1$ marker were not homologous in the GenBank search and AmR1 marker was revealed as unique sequences based on the GenBank search.

Two SCAR primer pairs $(A j R 1$ and $A m R 1)$ were designed according to the nucleotide sequences obtained by cloned RAPD fragments. The SCAR primers were then used to amplify the genomic DNA of both species. A single, distinct, and easily identifiable band specific to each species is shown in Figs. 1 and 2.

\section{Discussion}

A recent demand for the health-promoting medicinal herbal plants has been increasing. In parallel with this trend, Chinese medicines are second only to licorice in herb medicine imports. The active components of A. japonica and A. macrocephala are volatile oils. Sesquiterpenoids such as atractylon, atractylenolide III and $3 \beta$-acetoxyatractylon are the major oils, but the content levels are different between these two species (SAKAмото et al., 1996). Thus, it is an (indispensably) important issue to establish an assay system for the discrimination of the herbal medicines and provide a quality control. The first step in this process is to develop efficient markers.

Primers for SCAR marker can be selected on the basis of the nucleotide sequence of RAPD and is used to understand the existence of specific nucleotide sequence by PCR. For example, BEHURA et al. (1999) applied to SCAR marker for efficiently discriminating varieties of rice. SCAR markers have been practically applied to various fields such as identifying resistance gene (DEDRYVER et al., 1996) and thermo sensitive genes (LANG et al., 1999).

To develop a fast, cheap, and reliable PCR-based assay, NEGI et al. (2000) employed PCR-walking technology to isolate sequences adjacent to the linked RAPD. Based on the sequence information of the cloned flanking sequence of marker, new primers can be designed. In this study, the two pairs of primers designed from nucleotide sequences of the RAPD bands could produce specific SCAR markers (AjR1 and AmR1), and could be used to easily discriminate between $A$. japonica and A. macrocephala. With these two SCAR markers, Korean and Chinese herbal medicines in the Korean herbal market could be discriminated.

Consequently, the SCAR markers identified in this study will confer an efficient method for discriminating of their origins and unique reproductive modes in
Atractylodes species. The development of discriminative method for herbal medicines using SCAR marker is helpful to protect the unique national resources, to set up distribution system for Korean herbal market, protect home industries, and provide reliable medicines to consumers. Moreover, this study can assist in future selective breeding programs as reliable and reproducible molecular markers.

\section{References}

Altschul, F. S., L. Thomas, A. A. Madden, Schaffer, Z. Jinghui, Z. Zheng, M. WeB and D. J. LipMAN (1997): "Gapped BLAST and PSI-BLAST: a new generation of protein database search programs" Nucleic Acids Res. 25: 3389-3402.

Ardiel, G. S., T. S. Grewal, P. Deberdt, B. G. Rossnagel and G. J. SCOLES (2002): Inheritance of resistance to covered smut in barley and development of a tightly linked SCAR marker. Theor. Appl. Genet. 104: 457-464.

Bang, K. H., D. H. Koo, M. K. HuH, N. S. SEONG and J. W. BANG (2003): Physical mapping of the species-specific RAPD fragments and teromere sequence repeats between Atractylodes japonica and Atractylodes macrocephala. Korean J. Genet. 26: 77-81.

Barret, P., R. Delourme, N. Foisset and M. Renard (1998): Development of a SCAR marker for molecular tagging of the dwarf BREIZH $(B z h)$ gene in Brassica napus L. Theor. Appl. Genet. 97: 828-833.

Behura, S. K., S. C. Sahu, S. Rajamani, A. Devi, R. Mago, S. NAIR and M. MoHAN (1999): Differentiation of Asian rice gall midge, Orseolia oryzae (Wood-mason), biotypes by sequence characterized amplified regions (SCARs). Int. Mol. Biol. 8: 391-397.

Dedryver, F., M. F. Jubier, J. Thouvenin and H. Goyeau (1996): Molecular markers linked to the leaf rust resistance gene Lr24 in different shear cultivar. Genome 39: $830-835$.

Deng, Z., S. Huang, S. Xiao and F. G. Gmitter (1997): Development and characterization of SCAR markers linked to the citrus tristeza virus resistance gene from Poncirus trifoliata. Genome 40: 697-704.

Doyle, J. J. and J. L. DoYLE (1987): A rapid DNA isolation procedure for small quantities of fresh leaf tissue. Phytochem. Bull. 19: 11-15.

Hernandez, P., A. Martin and G. Dorado (1999): Development of SCARs by direct sequencing of RAPD products: a practical tool for the introgression and marker-assisted selection of wheat. Mol. Breed. 5: 245-253.

KIM, J. H., H. JounG, H. W. KIM and Y. P. LIM (1998): Estimation of genetic variation and relationship in potato (Solanum Tuberosum L.) cultivars using AFLP markers. Am. J. Potato Res. 75: 107-112.

LAHOGUe, F., P. This and A. Bonquet (1998): Identification of a codominant SCAR marker linked to the seedlessness character in grapevine. Theor. Appl. Genet. 97: 950-959.

Lang, N. T., P. K. Subudhi, S. S. Virmani, D. S. Brar, G. S. Khush, Z. Li and N. HuAng (1999): Development of PCR based markers for thermosensitive genetic male sterility gene $t m s 3(t)$ in rice (Oryza sativa L.). Hereditas 131: 121-127.

NAqVi, N. I. and B. B. ChAtтoo (1996): Development of a sequence characterized amplified region (SCAR) based indirect selection method for a dominant blast-resistance gene in rice. Genome 39: 26-30. 
Negi, M. S., M. Devic, M. Delseny and M. LaKshmikuMARAN (2000): Identification of AFLP fragments linked to seed coat colour in Brassica juncea and conversion to a SCAR marker for rapid selection. Theor. Appl. Genet. 101: $146-152$.

NEI, M. (1973): Analysis of gene diversity in subdivided populations. Proc Natl Acad Sci USA 70: 3321-3323.

NiCESE, F. P., J. I. Hormaza and G. H. McGranahan (1998): Molecular characterization and genetic relatedness among walnut (Juglans regia L.) genotypes based on RAPD markers. Euphytica 101: 199-206.

PARAN, I. and R. W. Michelmore (1993): Development of reliable PCR-based markers linked to downy mildew resistance genes in lettuce. Theor. Appl. Genet. 85: 985-993.
SAmbrook, J., R. MANiATIS and E. F. FRITSCH (1989): Molecular cloning; A laboratory manual. Cold Spring Harbor, New York.

SaKamoto, S., H. Kudo, S. Suzuki, S. SAssa, S. Yoshimura, T. Nakayama, M. Maemura, T. Mitamura, Z. QI, X. D. LiU, Y. YAGishita and A. Asai (1996): Pharmacotherapeutic effects of toki-shakuyaku-san on leukorrhagia in young women. Am. J. Chin. Med. 24: 165-168.

Williams, J. G. K., A. R. KubELIK, K. J. LivaK, J. A. RAFALSKI and S. V. TINGEY (1990): DNA polymorphism amplified by arbitrary primers are useful as genetic markers. Nucleic Acid Res. 18: 6531-6535.

\title{
Genetic Diversity of Two Evergreen Oaks [Quercus suber (L.) and Quercus ilex subsp. rotundifolia (Lam.)] in Portugal using AFLP Markers
}

\author{
By A. C. Coelho ${ }^{1), 2)}$, M. B. Lima ${ }^{3)}$, D. Neves ${ }^{4)}$ and A. Cravador ${ }^{1)}$
}

(Received 24 ${ }^{\text {th }}$ June 2005)

\begin{abstract}
The genetic variability of cork oak (Quercus suber, L.) in Portugal was evaluated by AFLP using five primer combinations. Three hundred and thirteen trees from three geographically contrasting regions exhibited a high level of genetic variation. The genetic profile of each individual is composed of 291 loci, randomly positioned in the genome and consists of monomorphic and polymorphic fragments. Similarities and dissimilarities among the individuals were quantitatively evaluated by numerical taxonomy. The overall sample shows a proportion of AFLP polymorphic markers of $71 \%$, denoting a high level of variability. Ninety percent of the polymorphic markers identified in cork oak genotypes are uniformly distributed throughout the cork oak populations of Algarve, Alentejo and Trás-os-Montes regions. The coefficients of genetic similarity vary from 0.61 to 0.88 implying that $60 \%$ of fragments found are common. A sample of 52 holm oak [Quercus ilex subsp. rotundifolia (Lam.)] trees from overlapping areas was also analysed by AFLP with the same five primer combinations. However the codification of markers together with those selected on cork oak profiles was feasible with only one

1) Universidade do Algarve, Faculdade de Engenharia dos Recursos Naturais, Campus de Gambelas, 8005-139 FARO, Portugal.

2) Universidade do Algarve, Escola Superior de Educação, Campus da Penha, 8005-139 FARO, Portugal.

3) Unidade de Taxonomia Numérica, Estação Agronómica Nacional, Quinta do Marquês, 2784-505 OEIRAS, Portugal.

4) Universidade do Algarve, Instituto Transfronteiriço Universitário para a Ciência, a Cultura e o Ambiente, Campus de Gambelas, 8005-139 FARO, Portugal.

A. CRAVADOR. e-mail: acravad@ualg.pt

A. C. CoelHo. e-mail: acoelho@ualg.pt
\end{abstract}

primer combination due to an apparent much higher polymorphism. AFLP and numerical taxonomy analysis enabled to differentiate the taxa and showed that the level of similarity observed between the profiles of the individuals from holm oak species was lower than that observed in cork oak, implying that apparently the degree of polymorphism is higher in $Q$. ilex subsp. rotundifolia than that quantified in $Q$. suber.

A Bayesian approach was used to assess $Q$. suber total genetic diversity $(\mathrm{Ht}=0.2534, \mathrm{P}<0.001)$ of which $1.7 \%$ $(F s t=0.0172, P<0.001)$ was assigned to differences among populations. Analysis of molecular variance (AMOVA) showed that most genetic variation is comprised within populations $(96 \%)$ while $3.6 \%$ is among populations ( $\Phi$ st $=0.036, P<0.001)$. Differences among populations within geographic regions account for $2.6 \%$ ( $\Phi$ sc $=0.026, P<0.001)$ of the total variation and only $1.3 \%$ ( $\Phi$ ct $=0.013, P=0.007$ ) is attributed to variation among regions denoting little differentiation of populations over a range of $700 \mathrm{~km}$.

Key words: AFLP, genetic diversity, genetic introgression, Quercus suber (L.), Quercus ilex subsp. rotundifolia (Lam.)

\section{Introduction}

Cork oak (Quercus suber L.), an evergreen species, is mainly distributed in the western Mediterranean Basin. The largest stands, covering about 700.000 ha are located in Portugal and correspond to $21 \%$ of the forest area in Portugal and to $30 \%$ of the world cork producing area. Cork oak plantations are very important for the economy and constitute a social and environmental issue that has to be taken into consideration as the unparalleled decline occurring in the Iberian Peninsula 